\title{
Sosyal Bilgiler Dersi 7. Sınıf Öğretim Programı "Yaşayan Demokrasi” Ünitesinin Kazanımlarına Ulaşma Derecesinin Öğretmen Görüşlerine Göre Değerlendirilmesi
}

\author{
Feyzullah Ezer ${ }^{\mathrm{a}}$ \& Sami Çelik ${ }^{\mathrm{a}}$ \\ ${ }^{\mathrm{a}}$ Ĕ̆itim Fakültesi, Fırat Üniversitesi, Elazı̆̆, Türkiye
}

\section{ÖZET}

$\mathrm{Bu}$ araştırmanın amacı, 7. Sınıf Sosyal Bilgiler Dersi "Yaşayan Demokrasi" Ünitesinin Kazanımlarına ulaşma derecesinin öğretmen görüşlerine göre değerlendirilmesidir. $\mathrm{Bu}$ değerlendirmenin yapılmasında cinsiyet, mesleki kıdem, mezun olunan lisans programı, öğrenim durumu gibi değişkenler esas alınmıștır. Betimsel nitelik arz eden nicel araștırma yöntemlerinden birisi olan betimleyici yöntemlerden, "alan taraması (survey)" yöntemi kullanılmıştır. Araştırma örneklemini, evreni temsil niteliğine sahip olan Elazığ İl Merkezinde bulunan 2014-2015 Eğitim Öğretim Yılında görev yapan ve ölçeği cevaplamayı kabul eden 106 Sosyal Bilgiler Öğretmeninden oluşturulmuştur. Verilerin elde edilmesinde, Koçyiğit (2002) tarafından geliştirilmiş ölçekten yararlanılmıştır. Bu çalışmada, anlamlılık düzeyi p=0.05 düzeyi kabul edilmiştir. Araştırmaya katılan Sosyal Bilgiler Öğretmenlerine göre öğrenciler, öğretim sürecinde ünitede yer alan beş kazanıma ulaşmışlardır. Ancak demokrasinin yaşaması adına bu kazanımların yeterli olmadıkları sonucuna da varılmıştır.

\section{MAKALE GEÇMIşí}

Gönderim 2 Kasım 2016

Kabul 13 Aralık 2016

\section{ANAHTAR KELIMELER}

Sosyal Bilgiler dersi; yaşayan demokrasi ünitesi; öğretmen görüşleri

\section{Giriș}

İnsanın sosyal bir varlık olması hasebiyle, sosyal bilimler veya sosyal bilgiler eğitiminin geçmişi insanlık tarihi kadar eskidir denilebilir. İnsanoğlu, tarihi boyunca eğitim yoluyla bireyin topluma ve çevreye uyumunu sağlamaya çalışmıştır. Bu çabalar zamanla sosyal bilimlerin temelini oluşturacak bilgilere zemin teşkil etmiştir. Böylece, genellikle sosyal bilimler içerisinde değerlendirilen sosyal bilgileri oluşturan disiplinler ortaya çıkmıştır (Koçoğlu, 2012).

Sosyal bilgiler genel itibarıyla sosyal bilimler içerisinde değerlendirilir ve içeriği çeşitli sosyal ve beşeri disiplinlerden oluşur. Çeşitli sosyal ve beşeri disiplinlere ait olgu, bilgi ve kavramların bir araya getirilmesinden oluşan sosyal bilgiler, çeşitli şekillerde tanımlanabilmektedir. Tanrı̈ğen (2006), sosyal bilgileri, insanları çeşitli yönleriyle irdeleyen ve araştıran bilimler topluluğu olarak ele alırken, Duverger (1990), esas olarak insanı ve iletişimini inceleyen bilim dalı şeklinde tanımlamaktadır. Sosyal bilgiler literatüründe önemli bir yere sahip, sosyal bilgileri, millet olma bilinci oluşturmak için bilimlerin bir araya gelmesi olarak tanımlamaktadır (Aktaran: Öztürk ve Ünal, 1999) .Safran'a (2004) göre ise, hayatı, insan ve toplum ekseninde analiz eden bilimler topluluğudur. Ross (1997) ise, yeni nesilin insanlar içinde bir konum ve mevki kazandı- 
rılması işlemi olarak tanımlamaktadır (Aktaran: Kılıçoğlu, 2012)

Sosyal Bilgiler Dersi, tarih, coğrafya, vatandaşlık, sosyoloji gibi birçok disiplin içeriğinin toplu öğretim mantığına göre bir araya getirilerek Sosyal Bilgiler Dersi Öğretim Programı ismiyle okutulan bir derstir. Bu dersin içeriği, farklı birçok disiplinden oluşmaktadır. Bunlar arasında tarih, coğrafya, sosyoloji, antropoloji, psikoloji, ekonomi, iletişim öne çıkan disiplinlerdir (Yazıcı, 2011). Türkiye'de gerek ilkokul ve gerekse ortaokul kademelerinde genel itibarıyla eğitimin amacına ulaşabilmesi bakımından Sosyal Bilgiler Dersi ve Sosyal Bilgiler Öğretimi büyük öneme sahiptir. Nitekim Milli Eğitim Bakanlığı tarafından Sosyal Bilgiler Dersi, miğfer derslerden birisi olarak belirlenmiştir. Bunun için de diğer disiplinlerle ilişki kurmak ve disiplinlerarası bir çalışma yapmak zorunlu olabilir (Akpınar, 2014).

Sosyal Bilgiler Dersinin amacı, bireyin içerisinde yaşadığı hayata hazırlanmasıdır. Bunun için öncelikle bireyin, sosyal bilgileri oluşturan disiplinler aracılığıly yaşadığı fiziki ve sosyal çevreyi tanıması ve bunlara uyum sağlaması önemlidir. Cumhuriyetin hemen başında 1926 yılında bugünkü ismiyle Sosyal Bilgiler Dersinin amacı, milli kimliğe ve milli bilince bağlı bir nesil yetiştirmektir (Kan, 2010). J. Dewey ise Sosyal Bilgiler Dersinin amacının medeniyeti ve demokrasiyi seven bir nesil var etmek olduğunu belirtmiştir. (Aktaran: Doğanay, 2008). Bilgi, analiz, inanç ve beceri kavramları üzerinde Sosyal Bilgiler Dersinin amacını birleştirmek mümkündür.

Bu araştırmada, Milli Eğitim Bakanlığı, Talim ve Terbiye Kurulu Başkanlığı’ nın 05.01. 2009 ve 2 sayılı kararı ile değiştirilen ve 2009-2010 Eğitim-Öğretim yılında yürürlüğe giren İlköğretim 7. Sinıflar Sosyal Bilgiler Dersi Öğretim Programı 'Yaşayan Demokrasi' ünitesinin kazanımlarına ulaşma derecesinin öğretmen görüşlerine göre değerlendirilmesi incelenmiştir. Bu programda 'Yaşayan Demokrasi' ünitesi doğrudan verilecek beceriler arasında yer alan 'Karar verme' becerisi ile ilişkili verilmektedir. İlköğretim 7. Sınıflar Sosyal Bilgiler Dersi Öğretim Programı 'Yaşayan Demokrasi' ünitesinin kazanımlarına ulaşılması, öğrencilerin kişisel ve sosyal gelişimleri için olduğu kadar, Türkiye'de demokrasinin tüm kurum ve kuruluşlarıyla yerleşip, sürmesi ve geliştirilmesi bakımından da gereklidir. Dolayısıyla bir toplumu var eden ve yaşatan demokrasiyi eğitimden ayrı düşünemeyiz. Öyle ki "Demokrasi, eğitimle öğrenilebilir" söylemi genel kabul görmektedir. Buna bağlı olarak, bir değerler sistemi olan demokrasinin öğrenileceği en önemli mekânlar okullardır denilebilir. Demokratik bir siyasi sistemde eğitimin, özellikle de sosyal bilgiler eğitiminin en temel görevi, insanlara demokrasiyi özümsetmektir (Okutan, 2010; Özpolat, 2010). Bu bakımından, İlköğretim 7. Sınıflar Sosyal Bilgiler Dersi Öğretim Programı 'Yaşayan Demokrasi' ünitesinin kazanımlarına ulaşılması konusundaki öğretmen görüşlerinin belirlenmesi önemlidir.

\section{Araştırmanın amacı}

$\mathrm{Bu}$ araştırmanın amacı, 7. Sınıf Sosyal Bilgiler Dersi "Yaşayan Demokrasi” Ünitesinin Kazanımlarına ulaşma derecesinin öğretmen görüşlerine göre değerlendirilmesidir. Araştırmada bu genel amaç doğrultusunda aşağıdaki alt amaçlarda belirtilen sorulara cevap aranmıştır. 


\section{Alt amaçlar}

1. Yedinci Sınıf sosyal bilgiler öğretmenlerinin "Yaşayan Demokrasi” ünitesinin kazanımlarına yönelik görüşleri nelerdir?

2. Yedinci Sınıf sosyal bilgiler öğretmenlerinin "Yaşayan Demokrasi” ünitesinin kazanımlarına yönelik görüşleri cinsiyet değişkenine göre değişmekte midir?

3. Yedinci Sınıf sosyal bilgiler öğretmenlerinin "Yaşayan Demokrasi" ünitesinin kazanımlarına yönelik görüşleri mesleki kıdem değişkenine göre değişmekte midir?

4. Yedinci Sınıf sosyal bilgiler öğretmenlerinin "Yaşayan Demokrasi" ünitesinin kazanımlarına yönelik görüşleri mezun olunan lisans programı değişkenine göre değişmekte midir?

5. Yedinci Sınıf sosyal bilgiler öğretmenlerinin "Yaşayan Demokrasi” ünitesinin kazanımlarına yönelik görüşleri öğrenim durumu değişkenine göre değişmekte midir?

\section{Yöntem}

\section{Evren ve Örneklem}

Araştırma evrenini, 2014 - 2015 Eğitim Öğretim Yılında Elazığ İl Merkezinde bulunan Milli Eğitim Bakanlığına bağlı ortaokullarda görev yapan toplam 233 Sosyal Bilgiler Öğretmeni oluşturmaktadır. Araştırma örneklemini ise, evreni temsil niteliğine sahip olan Elazığ İl Merkezinde bulunan 2014-2015 Eğitim Öğretim Yılında görev yapan ve ölçeği cevaplamayı kabul eden toplam 106 Sosyal Bilgiler Öğretmeni (46 Kadın ve 60 Erkek) oluşturmuştur. Araştırmanın örneklemini teşkil eden öğretmenlerin çeşitli değişkenlere göre dağılımı Tablo 1'de görülmektedir.

Tablo 1 Araştırmanın örneklemini oluşturan öğretmenlerin demografik değişkenlere göre dağılımı

\begin{tabular}{|c|c|c|c|}
\hline Değişkenler & & $\mathbf{N}$ & $\%$ \\
\hline \multirow{2}{*}{ Cinsiyet } & Kadın & 46 & 43,4 \\
\hline & Erkek & 60 & 56,6 \\
\hline \multirow{4}{*}{ Kidem } & $1-5$ Y1l & 24 & 22,6 \\
\hline & $6-10 Y_{1} 1$ & 26 & 24,5 \\
\hline & 11-15 Y11 & 30 & 28,3 \\
\hline & 16 ve üzeri Y 11 & 26 & 24,5 \\
\hline \multirow{3}{*}{ Mezuniyet Türü } & Ön lisans & 2 & 1,9 \\
\hline & Lisans & 92 & 86,8 \\
\hline & Lisansüstü & 12 & 11,3 \\
\hline \multirow{3}{*}{ Lisans Türü } & Tarih & 39 & 36,8 \\
\hline & Coğrafya & 11 & 10,4 \\
\hline & Sos. Bil. Öğrt. & 56 & 52,8 \\
\hline Toplam & & 106 & 100.0 \\
\hline
\end{tabular}

\section{Verilerin Toplanması ve Analizi}

Araştırmada 7. Sınıf Sosyal Bilgiler Dersi “Yaşayan Demokrasi” ünitesinin kazanımlarına 
ulaşma derecesine yönelik verilerin elde edilmesinde, Koçyiğit (2002) tarafından geliştirilmiş ölçekten yararlanılmıştır. Araştırmada kullanılan ölçek likert tipinde olup, "Tamamen katılıorum=5", "Katılıorum=4", "Kismen katiliyorum=3", "Katılmıyorum=2", "Hiç katılmıyorum=1" şeklinde derecelendirilmiştir. Ölçek; kişisel bilgiler ve "Yaşayan Demokrasi” ünitesinin kazanımlarına yönelik görüşler olmak üzere iki kısımdan oluşmaktadır.

Verilerin analizinde; öğretmen görüşleri, değişkenler dikkate alınmadan aritmetik ortalama ve standart sapma teknikleri ile çözümlenerek yorumlanmıştır. Söz konusu görüşlerin değişkenler dikkate alınarak analizinde ise öncelikle maddelere homojenlik testi uygulanmış; homojen maddeler, ikili karşılaştırmalarda bağımsız gruplar "t” testi; çoklu karşılaştırmalarda ise tek yönlü varyans analizi (Anova) ile analiz edilmiştir. Gruplar arası anlamlı farklılığın belirlendiği durumlarda Scheffe veya LSD testi kullanılmıştır. Homojen olmayan maddelere yönelik veriler ise, ikili karşılaştırmalarda Mann Whitney U Testi (MWU); çoklu karşılaştırmalarda Kruskal Wallis Testi (KWH) ile analiz edilerek, yorumlanmıştır. Bunun için anlamlılık düzeyi $\mathrm{p}=0.05$ düzeyi kabul edilmiştir. $\mathrm{Bu}$ çalışmada, sadece öğretmen görüşleri arasında değişkenlere göre anlamlı olan maddeler yorumlanmıştır.

\section{Bulgular ve Yorum}

Araştırmaya katılan Sosyal Bilgiler Öğretmenlerinin görüşlerine göre, "Yaşayan Demokrasi” ünitesi kazanımlarına ulaşma düzeyine yönelik görüşlerinin dağılımı Tablo 2'de görülmektedir.

Tablo 2 Sosyal bilgiler dersi öğretim programı yaşayan demokrasi ünitesinin kazanımlarına ulaşma düzeyine yönelik öğretmen görüşleri

\begin{tabular}{|c|c|c|}
\hline Madde no & $\bar{X}$ & ss \\
\hline $\begin{array}{l}\text { 1. Öğrenciler, öğretim sürecinde "Tarihsel süreçte Türk Devletlerinde yönetim şekli ve } \\
\text { egemenlik anlayışındaki değişim ve sürekliliği fark eder" kazanımına ulaşmışlardır. }\end{array}$ & 3.68 & .75 \\
\hline 2. Öğrenciler, öğretim sürecinde "Anayasamızın 2. Maddesinde yer alan Türkiye Cumhuriyeti & 3.67 & .82 \\
\hline $\begin{array}{l}\text { Devleti'nin nitelikleriyle ilgili uygulamalara toplum hayatından örnekler verir " kazanımına } \\
\text { ulaşmışlardır }\end{array}$ & & \\
\hline
\end{tabular}

3. Öğrenciler, öğretim sürecinde "Türkiye Cumhuriyeti Devletinin yönetim yapısını: yasama, $3.65 \quad .81$ yürütme ve yargı kavramları çerçevesinde analiz eder " kazanımına ulaşmışlardır

4. Öğrenciler, öğretim sürecinde "Siyasi partilerin, sivil toplum örgütlerinin, medyanın ve $3.50 \quad .83$ bireylerin gündemi ve yönetimin karar alma süreçlerini ne şekilde etkilediğini örnekler üzerinden tartışır " kazanımına ulaşmışlardır

5. Öğrenciler, öğretim sürecinde "İçinde bulunduğu eğitsel ve sosyal faaliyetlerde işleyen $3.38 \quad .86$ süreçleri demokrasinin ilkeleri açısından analiz eder” kazanımına ulaşmışlardır. 
Tablo 2’ye göre, 7. Sınıf Sosyal Bilgiler Dersi öğretmenlerinin; öğrencilerin, ünite kazanımlarına ulaşmasına dair maddeleri benimseme dereceleri şöyledir: Öğrenciler, "Tarihsel süreçte Türk Devletlerinde yönetim şekli ve egemenlik anlayışındaki değişim ve sürekliliği fark eder” kazanımına ulaşmışlardır” (1=3.68). “Öğrenciler, öğretim sürecinde "Anayasamızın 2. Maddesinde yer alan Türkiye Cumhuriyeti Devleti'nin nitelikleriyle ilgili uygulamalara toplum hayatından örnekler verir " kazanımına ulaşmışlardır" (2=3.67). “Öğrenciler, öğretim sürecinde "Türkiye Cumhuriyeti Devleti'nin yönetim yapısını: yasama, yürütme ve yargı kavramları çerçevesinde analiz eder" kazanımına ulaşmışlardır $(3=3.65)$. "Öğrenciler, öğretim sürecinde "Siyasi partilerin, sivil toplum örgütlerinin, medyanın ve bireylerin gündemi ve yönetimin karar alma süreçlerini ne şekilde etkilediğini örnekler üzerinden tartışır ” kazanımına ulaşmışlardır” (4=3.50).

Buna göre, araştırmaya katılan Sosyal Bilgiler Öğretmenleri, araştırma ölçeğinin birinci alt boyutunu oluşturan ünitenin kazanımlarına ulaşılmasına dair maddelerden ilk dördünü "katıllyorum" düzeyinde benimsemişlerdir. Ancak araştırmaya katılan SBÖ, "Öğrenciler, öğretim sürecinde "İçinde bulunduğu eğitsel ve sosyal faaliyetlerde işleyen süreçleri demokrasinin ilkeleri açısından analiz eder kazanımına ulaşmışlardır” maddesinde kararsız (5=3.38) kalmışlardır.

Tablo 2'de yer alan maddelere yönelik Öğretmenlerin görüşleri arasında cinsiyet değişkenine göre anlamlı fark bulunamamıştır. Tablo 2'de yer alan 1. maddeye yönelik öğretmen görüşleri arasında kıdem değişkenine göre anlamlı fark vardır (KWH=4,769; $\mathrm{p}=0,039$ ). Non-parametrik olan bu madde (Levene $\mathrm{F}=3,690 ; \mathrm{p}=0,014$ ) için yapılan $\mathrm{MWU}$ testi (MWU=253,000; p=0.033), bu farkın I. Grup (1-5 Yıl) ile III. Grup (16 Yıl ve üstü) arasında olduğunu göstermiştir. Buna göre, “Öğrenciler, öğretim sürecinde 'Tarihsel süreçte Türk Devletlerinde yönetim şekli ve egemenlik anlayışındaki değişim ve sürekliliği fark eder' kazanımına ulaşmışlardır” görüşünü, 1-5 Yıl kıdeme sahip öğretmenler (MR1=27,96), 16 Yıl ve üstü kıdeme sahip olanlara göre $(M R 4=23,23)$ daha fazla benimsemişlerdir.

Tablo 2'de yer alan 2. maddeye yönelik öğretmen görüşleri arasında mezuniyet değişkenine göre anlamlı fark vardır[(F2-103=3.289; $\mathrm{p}=0,036)]$. Parametrik olan bu madde için yapılan LSD testi, bu farkın II. Grup (lisans) ve III. Grup (lisansüstü) arasında olduğunu göstermiştir. Buna göre “Öğrenciler, öğretim sürecinde 'Anayasamızın 2. Maddesinde yer alan Türkiye Cumhuriyeti Devleti'nin nitelikleriyle ilgili uygulamalara toplum hayatından örnekler verir’ kazanımına ulaşmışlardır” görüşünü, lisansüstü mezunu Sosyal Bilgiler Öğretmenleri $(3=3.71)$, lisans mezunu Sosyal Bilgiler Öğretmenlerine göre $(2=3.58)$ daha fazla benimsemişlerdir.

Mezun olunan lisans türü değişkenine göre, Tablo 1'de yer alan 3. [(F2-103=3.301; $\mathrm{p}=0,041)]$, 4. $[(\mathrm{F} 2-103=4.862 ; \mathrm{p}=0,010)]$ ve 5. $[(\mathrm{F} 2-103=4.938 ; \mathrm{p}=0,009)]$ maddelere yönelik öğretmen görüşleri arasında anlamlı fark vardır. Parametrik olan bu maddeler için LSD testi yapılmış ve sonuçları aşağıda verilmiştir:

3. Madde "Öğrenciler, öğretim sürecinde 'Türkiye Cumhuriyeti Devleti'nin yönetim yapısını: yasama, yürütme ve yargı kavramları çerçevesinde analiz eder' kazanımına ulaşmışlardır” görüşünü, lisansı tarih olan Öğretmenler $(1=3.76)$, lisansı coğrafya olan Öğretmenlere göre $(2=3.09)$ daha fazla benimsemişlerdir. "Öğrenciler, öğretim sürecinde 'Siyasi partilerin, sivil toplum örgütlerinin, medyanın ve bireylerin gün- 
demi ve yönetiminkarar alma süreçlerini ne şekilde etkilediğini örnekler üzerinden tartışır’ kazanımına ulaşmışlardır” şeklindeki görüşü (madde 4), lisansı sosyal bilgiler olan öğretmenler (3=3.64), coğrafya mezunu öğretmenlere göre $(2=2.81)$ daha fazla benimsemişlerdir. Madde 5 olan "Öğrenciler, öğretim sürecinde 'İçinde bulunduğu eğitsel ve sosyal faaliyetlerde işleyen süreçleri demokrasinin ilkeleri açısından analiz eder' kazanımına ulaşmışlardır” görüşünü, lisansı tarih olan öğretmenler $(1=3.49)$, coğrafya mezunu öğretmenlere göre $(2=2.63)$ daha fazla benimsemişlerdir.

\section{Sonuç ve Tartışma}

Araştırmaya katılan Sosyal Bilgiler Öğretmenlerine göre, öğrenciler, öğretim sürecinde ünitede yer alan şu kazanımlara ulaşmışlardır: "Tarihsel süreçte Türk Devletlerinde yönetim şekli ve egemenlik anlayışındaki değişim ve sürekliliği fark eder". "Anayasamızın 2. Maddesinde yer alan Türkiye Cumhuriyeti Devleti'nin nitelikleriyle ilgili uygulamalara toplum hayatından örnekler verir ". "Türkiye Cumhuriyeti Devleti'nin yönetim yapısını: yasama, yürütme ve yargı kavramları çerçevesinde analiz eder". "Siyasi partilerin, sivil toplum örgütlerinin, medyanın ve bireylerin gündemi ve yönetimin karar alma süreçlerini ne şekilde etkilediğini örnekler üzerinden tartışır”. Sosyal bilgiler dersi öğretmenlerinin, öğrencilerin, öğretim sürecinde "Yaşayan Demokrasi" ünitesinde yer alan bu dört kazanıma ulaştıkları şeklindeki görüşleri, bu programın uygulamadaki başarısını gösterdiği gibi, öğretmenlerin programa yönelik olumlu görüşlere sahip olduklarını da göstermektedir. Bu bulgu, 2004 yılından sonra geliştirilen Sosyal Bilgiler Dersi Öğretim Programı hakkında olumlu tutuma sahip oldukları şeklindeki benzer araştırma sonuçlarıyla (Ersoy ve Kaya, 2008; Dinç ve Doğan, 2010; Memişoğlu, 2012; Bahar, Özkaya ve Birol, 2008) paralellik göstermektedir. Bu durum, ünitenin uygulamadaki etkililiği ve başarısı bakımından önemlidir. Buna göre, araştırma örnekleminde yer alan okullarda 7. Sınıf "Yaşayan Demokrasi” ünitesinin sözü geçen kazanımları uygulamada etkilidir denilebilir. Ancak aynı Sosyal Bilgiler Öğretmenlerinin, öğretim sürecinde, öğrencilerin sözü geçen dört kazanıma ulaştıkları şeklindeki maddeleri, ilgili ölçekte yer alan "tamamen katılıyorum" derecesi ile değil de, bir alt derece olan "katılıyorum" derecesi ile benimsemiş olmaları, dikkat çekicidir. Araştırma örneklemini teşkil eden öğretmenlerin, konuyla ilgili maddeleri benimseme derecesine dayalı olarak şu sonuca ulaşılabilir: Araştırmanın yürütüldüğü bağlam ve sınırlılıklar çerçevesinde, ünitenin ilk dört kazanımı, uygulamada etkilidir ve öğretim sürecinde bu kazanımlar ulaşılabilirdir. Ünitenin ilk dört kazanımının uygulamadaki bu etkililiği, programda yer alan ilk dört kazanımının nitelikleri, uygulama koşullarının (öğretim sürecinin) uygunluğu ve öğretmenlerin niteliklerine bağlı olabilir.

Araştırmada, mesleki kıdem değişkenine göre, "Öğrenciler, öğretim sürecinde 'Tarihsel süreçte Türk Devletlerinde yönetim șekli ve egemenlik anlayıșındaki değișim ve sürekliliği fark eder' kazanımına ulaşmışlardır” görüşünü, 1-5 Yıl kıdeme sahip Sosyal Bilgiler Öğretmenlerinin, 16-20 Yıl kıdeme sahip olanlara göre daha fazla benimsemiş olduğu bulgusuna ulaşılmıştır. Bu bulgu, sözü geçen kazanıma ulaşma konusunda genç öğretmenlerin, kıdemlilere göre daha iyimser olduğu şeklinde yorumlanabilir. Bu iyimserlik, 1-5 Yıl kıdeme sahip öğretmenlerin yeterince deneyime sahip olmamaları ile ilgili olabileceği gibi, kıdemli öğretmenlere göre lisans eğitimleri sırasında daha iyi yetiştirilmeleri ile de ilgili olabilir. 1- 5 Yıl kıdeme sahip öğretmenlerin, 'Tarihsel süreçte 
Türk Devletlerinde yönetim şekli ve egemenlik anlayışındaki değişim ve sürekliliği fark eder' kazanımına ulaşma konusundaki iyimserliklerinin nedenini belirlemek için daha detaylı araştırmalara ihtiyaç vardır.

Araştırmada, Öğretmenlerin Tablo 2'de yer alan maddelere yönelik görüşleri arasında mezuniyet değişkenine göre anlamlı farklılık olduğu bulgusuna ulaşılmıştır. Bu bulgu, "Öğrenciler, öğretim sürecinde 'Anayasamızın 2. Maddesinde yer alan Türkiye Cumhuriyeti Devleti'nin nitelikleriyle ilgili uygulamalara toplum hayatından örnekler verir' kazanımına ulaşmışlardır” görüşünü, lisansüstü mezunu Sosyal Bilgiler Öğretmenlerinin, lisans mezunu Öğretmenlere göre, daha fazla benimsemiş olduğu şeklindedir. Bu bulgu, “Anayasamızın 2. Maddesinde yer alan Türkiye Cumhuriyeti Devleti'nin nitelikleriyle ilgili uygulamalara toplum hayatından örnekler verir” kazanımına ulaşma konusunda, lisansüstü mezunu Öğretmenlerin daha olumlu görüşe sahip oldukları biçiminde yorumlanabilir. Bunun olası bir nedeni, lisansüstü eğitiminin Sosyal Bilgiler Öğretmenlerine daha üst düzeyde öğretim bilgi ve becerisi kazandırmış olmasıdır.

Araştırmada, "Öğrenciler, öğretim sürecinde 'Siyasi partilerin, sivil toplum örgütlerinin, medyanın ve bireylerin gündemi ve yönetimin karar alma süreçlerini ne şekilde etkilediğini örnekler üzerinden tartışır’ kazanımına ulaşmışlardır” şeklindeki görüşü (madde 4), lisansı Eğitim Fakültesi Sosyal Bilgiler Öğretmenliği olan öğretmenlerin, coğrafya mezunu öğretmenlere göre daha fazla benimsemiş oldukları belirlenmiştir. Ağırlıklı olarak vatandaşlık disiplini ile ilgili olan bu kazanımın, bu konuda eğitim almış olan Sosyal Bilgiler Öğretmenlerinin, bu konuda eğitim almamış olan coğrafya mezunu öğretmenlere göre daha olumlu görüşlere sahip olmaları, beklenen bir sonuçtur. Çünkü öğretmenlerin eğitim aldığı konuda daha başarılı olması ve dolayısıyla da, öğretim sürecinde öğrencilerini buna ilişkin kazanıma ulaştırma konusunda olumlu görüşlere sahip olmaları beklenir. Aynı ünitede yer alan "İçinde bulunduğu eğitsel ve sosyal faaliyetlerde işleyen süreçleri demokrasinin ilkeleri açısından analiz eder" kazanımına ulaşma konusunda, lisansı tarih olan Sosyal Bilgiler Öğretmenlerinin, coğrafya mezunu Sosyal Bilgiler Öğretmenlerine göre daha olumlu görüşe sahip olmaları da, bu kazanımın ağırlıklı olarak tarih ve sosyal bilgilerle ilgili olması ile ilgili olabilir. Bu ve benzeri konularda eğitim almamış olan ve süreç içerisinde de kendisini geliştirmemiş olan coğrafya mezunu Sosyal Bilgiler Öğretmenlerinin, konuyla ilgili kazanımların öğretiminde daha az başarılı olmaları şaşırtıcı değildir. Diğer bir olasılık ise, araştırmaya katılan öğretmenlerin, sözü geçen kazanıma dair içeriğe ilişkin ilgilerinin istenilen düzeyde olmamasıdır. Bu konuda, Tonga ve Uslu (2015) yürüttükleri araştırmada, sosyal bilgiler öğretmen adaylarının, tarih dersine oranla coğrafya dersine karşı daha ilgili ve istekli olduğu görülmüştür.

Not: Bu makale Yrd. Doç. Dr. Feyzullah EZER’in danışmanlığında Sami ÇELİK tarafından hazırlanan “ Sosyal Bilgiler Dersi 7. Sınıf Öğretim Programı "Yaşayan Demokrasi” Ünitesinin Kazanımlarına Ulaşma Derecesinin Öğretmen Görüşlerine Göre Değerlendirilmesi “ adlı Yüksek Lisans Tezinden üretilmiştir.

\section{Kaynakça}

Akpınar, B. (2014). Eğitimde Program Geliştirme. Ankara: Data Yayıncılık.

Bahar, H.H., Özkaya, F. ve Birol, N. (2008). Dördüncü Sınıf Sosyal Bilgiler Dersi Öğretim Programına İlişkin Öğretmen Görüşlerinin Değerlendirilmesi. XVIII. Ulusal Eğitim Bilimleri Kurultayı. 1-3 Eylül 2008 Sakarya Üniversitesi Eğitim Fakültesi. 
Barth, J.,L. (1991). Elementary and Junior High/Middle School Social Studies Curriculum. Activites and Materials. Lanham/New York/London: Universtiy Pres of America.

Dinç, E. ve Doğan, Y. (2010). İlköğretim İkinci Kademe Sosyal Bilgiler Öğretim Programı ve Uygulanması Hakkında Öğretmen Görüşleri. Journal of Social Studies Education Research, 1(1), 33-41.

Doğanay, A. (2008). Çağdaş Sosyal Bilgiler Anlayışı Işı̆̆ında Yeni Sosyal Bilgiler Programının Değerlendirilmesi. Ç.Ü. Sosyal Bilimler Enstitüsü Dergisi, 17 (2), 77-96.

Duverger, M. (1990). Sosyal Bilimlere Giriş. Ankara: Bilgi Yayınevi.

Ersoy, F. ve Kaya, E. (2008). Sınıf Öğretmenlerine Göre Öğrencilerin Sosyal Bilgiler Dersi Öğretim Programına (2004) İlişkin Yaklaşımları. Anadolu Üniversitesi Sosyal Bilimler Dergisi, 8(1), 53-62.

Kan, Ç. (2010). A.B.D ve Türkiye'de Sosyal Bilgilerin Tarihsel Gelişimi. GÜ, Gazi Eğitim Fakültesi Dergisi, 30 (2), 663-672.

Kılıçoğlu, G. (2012). "Sosyal Bilgiler Tanımı, Dünyada ve Ülkemizde Gelişimi ve Önemi" İçinde Sosyal Bilgiler Öğretimi (Ed: Mustafa Safran). Ankara: Pegem Yayıncılık.

Koçoğlu, E. (2012). Cumhuriyetten günümüze insan hakları ve demokrasi kavramları açısından Sosyal Bilgiler Dersi Eğitim Programının incelenmesi. Dicle Üniversitesi Sosyal Bilimler Enstitüsü Dergisi, 4 (7), 1-20.

Koçyiğit, Ş. (2002). İlköğretim 2. Kademede Sosyal Bilgiler Dersinin Hedeflerini Ulaşma Derecesi, Yayımlanmamış Yüksek Lisans Tezi, Niğde Üniversitesi Sosyal Bilimler Enstitüsü, Niğde.

Memişoğlu, H. (2012). İlköğretim 4-5 Sosyal Bilgiler Ders Programinin Öğretmen Görüşlerine Göre Değerlendirilmesi. Eğitim ve Öğretim Araştırmaları Dergisi. 1, 66-81.

Okutan, M. (2010). Türk Eğitim Sistemi’nde Demokrasi Eğitimi. Uluslararası İnsan Bilimleri Dergisi, 7(1), 938-946.

Özpolat, A. (2010). Bir Toplumsal Değişme Paradigmasi Olarak Demokrasinin Eğitime Yansımaları: Demokratik Eğitim. Milli Eğitim, 185, 365-381.

Öztürk, C. ve Ünal, S. (1999). Sınıf Öğretmenlerinin Sosyal Bilgiler Dersine Karşı Tutumu. Pamukkale Üniversitesi Eğitim Fakültesi Dergisi, 6, 1-9.

Safran, M. (2004). İlköğretim Programlarında Yeni Yaklaşımlar Sosyal Bilgiler (4-5. sınıf). Bilim ve Aklın Aydınlığında Eğitim Dergisi, 12, 54-55.

Tanrıöğen, A. (2006). Hayat ve Sosyal Bilgiler Öğretimi Etkili Vatandaş Yetiştirme İçinde (Ed. A. Tanrı̈ğen), Hayat Bilgisi ve Sosyal Bilgiler Öğretimi. Ankara: Lisans Yayıncılık.

Tonga, D. ve Uslu, S. (2015). Sosyal Bilgiler Dersinde Kazanım-Değer İlişkisi. Ahi Evran Üniversitesi Kırşehir Eğitim Fakültesi Dergisi (KEFAD),16 (1), 91-110.

Yazıcı, K. (2011). Sosyal Bilgiler Öğretmen Adaylarının Demokratik Değerlerinin Çeşitli Değişkenler Açısından İncelenmesi. Eğitim ve Bilim, 36 (159), 165-178. 


\title{
SUMMARY
}

\section{Evaluating the Extent of Reaching the Objectives of the Unit "Alive Democracy" in 7th Grade Social Science Curriculum Based on Teachers' Opinion}

Keywords: Social studies, living democracy unit, teachers' opinions

\begin{abstract}
Aim and Method
The aim of the research is evaluating the extent of reaching the objectives of the unit "alive democracy" in 7th grade social science curriculum based on teachers' opinion.

While evaluating, some variations such as gender, profession experience, graduation program and educational background were taken into consideration. For this study, survey was used. The sample of the research is 106 social science teachers who were working in Elazığ province in Turkey during 2014-2015 education years. To obtain the data, a survey developed by Koçyiğit (2002) was used. To analyze the data, arithmetic mean, standard deviation calculations, for homogenous deviation, t-test and variance analysis, for nonhomogenous deviation MWU and KWH tests were used.
\end{abstract}

\section{Introduction}

Because of being a social being of human, social science and social science education are as old as humanity history. Social science which is formed by using social and humanities can be described several ways. Barth (1991) describes social science as bringing sciences together to form a nationality consciousness (Öztürk ve Ünal, 1999). According to Safran (2004), social science is the combination of sciences which analyze life based on experiences of both a person and society. Ross (1997, cited: Kılıçoğlu, 2012), it is defined as the process of reaching a satisfactory position and status for generations to come.

To purpose of social science course is to prepare a person to the society in which he lives. Through this course which dates back 1926, adaptation to the physical and social environment of a person is important. However, it should be discussed that how much of this is provided in practice by the course content. Therefore, determining the teachers' opinion is important to evaluate the extent of reaching the objectives of the unit "alive democracy" in 7th grade social science curriculum

\section{Findings}

According to the participant teachers, students have obtained the objectives of the "Alive Democracy" unit in 7th Grade social science course curriculum at desired levels. Moreover, teachers have adopted the objectives of the unit. Therefore, participant teachers have adopted the objectives of the "Alive Democracy" unit in 7th Grade social science course curriculum and they have thought that its application is successful. While there is no difference among teacher's opinion according to gender, there is a meaningful difference according to working experience. Young teachers (1-5 Year) adopt the objectives better than 
16 Year and over experienced teachers do. The difference among teachers' opinion related to graduation is in favor of master degree social Science Teachers. According to graduation type, history teachers adopt the objectives better than geography teachers.

\section{Discussion and Results}

Respondent teachers have adopted the objectives of the "Alive Democracy" unit in 7th Grade social science course curriculum and they think students have reached the objectives. Hence, it can be said that teachers have positive attitude towards social science course curriculum which was developed in 2004. Similarly, Ersoy and Kaya (2008), Dinç and Doğan (2010), Memişoğlu (2012), and Bahar, Özkaya and Birol (2008) have reached similar results. This situation is important for the effectiveness of application and success rates.

Young teachers' being more optimist towards objectives of the "Alive Democracy" unit in 7th Grade social science course curriculum may be the result of being their insufficient amount of experiences or because of their up-to-date university education that matches days' requirements better. Teachers with a master's degree have more positive attitude towards these objectives rather than teachers with only a bachelor's degree may be the result of their higher and deeper level of knowledge and comprehension of teaching job requirements. History teachers adopting the objectives better than geography teachers has been an expected result. Because the objectives are mostly about history and social science. Similarly Ulusoy and Gülüm's (2009) research results are in line with these findings.

Finally, the objectives of the "Alive Democracy" unit in 7th Grade social science course curriculum are suitable for students' personal features and suitable to be applied. However, it doesn't mean this curriculum is perfect. There should be continuously revised according to the feedback of application of the theoretical content. Therefore, curriculum development can be defined as a process which has continuous characteristics. This situation is doubtlessly valid for 7 th Grade social science course curriculum as well. 